Jurnal Manajemen dan Bisnis MEDIA EKONOMI, Vol . XIX No 2 Juli 2019

\title{
OPTIMALISASI DESA WISATA SUGIHWARAS KECAMATAN NGANCAR TERKAIT BUMDESA OLEH PEMERINTAH DESA DAN BPD
}

\author{
Bambang Agus Sumantri \\ Mahasiswa Program Doktor Ilmu Manajemen, Universitas Jenderal Soedirman \\ bambang.as@unpkediri.ac.id \\ Poniran Yudho Leksono Dan Dian Rosilawati \\ Manajemen Fakultas Ekonomi Universitas Nusantara PGRI Kediri
}

\begin{abstract}
Abstrak
Penelitian ini bertujuan untuk mengetahui dan menganalisis potensi Desa Wisata Sugihwaras dan mengetahui pemahaman pemerintah desa dan BPD Desa Wisata Sugihwaras terkait BUM Desa. Populasi terdiri 14 orang yang diambil tanpa membedakan jenis kelamin, pendidikan, dan pengalaman kerja. Metode pengumpulan data, sumber data primer diperoleh dari kuesioner tertutup dengan skor penilaian jawaban $1=$ benar dan $0=$ salah, kepada pemerintah desa (kades dan perangkat desa) dan Badan Permusyawaratan Desa (BPD) dengan pertanyaan pilihan ganda memilih yang tepat kemudian dijelaskan dengan statistik deskriptif (prosentase). Selain itu, data primer juga didapat dari hasil observasi dan wawancara. Sedangkan data sekunder yang diperoleh dari dokumen yang berkaitan dengan dokumen data potensi desa. Hasil penelitian yang terkait dengan Optimalisasi Desa Wisata Sugihwaras Kecamatan Ngancar dalam perspektif BUM Desa oleh pemerintah desa dan BPD selaku pembuatan kebijakan. 1. Potensi Desa Wisata Sugihwaras belum terkelola dengan standar padahal memiliki potensi. 2. Terdapat pemahaman terkait BUMDesa dengan hasil sebagai berikut: $7 \%$ (tujuh persen) kategori sangat kurang paham; 71 \% (tujuh puluh satu persen) kategori kurang paham; $14 \%$ (empat belas persen) kategori cukup paham; dan $7 \%$ (tujuh persen) kategori paham. Serta $0 \%$ (nol persen) kategori sangat paham. Jadi program optimalisasi potensi desa wisata dan peran BUMDesa secara berlanjutan dan intensif perlu dilakukan oleh pihak pemerintah desa dan BUMDesa.
\end{abstract}

Kata kunci: optimalisasi, potensi, desa wisata, pemerintahan desa, BUM Desa.

\begin{abstract}
This research study is to study and analyze the potential of Sugihwaras Tourism Village and to know the understanding of village government and BPD Sugihwaras Tourism Village related to BUM Desa. The population consisted of 14 people drawn regardless of sex, education, and work experience. Data collection methods, primary data sources obtained from closed questionnaires with response scores $1=$ true and $0=$ false, for the village government (village head and village apparatus) and the Village Consultative Body (BPD) with multiple choice questions selected according to the report descriptive (percentage). In addition, primary data were also obtained from observations and interviews. Whereas secondary data obtained from documents related to village data potential documents. The results of research related to Optimization of Sugihwaras Tourism Village in Ngancar District in the perspective of BUM Desa by the village government and BPD as policy making. 1. Potential Sugihwaras Tourism Village has not been managed by standards even though it has potential. 2. Get an understanding related to BUMDesa with the following results: 7\% (seven percent) category is very poor in understanding; $71 \%$ (seventy one percent) of the category of lack of understanding; $14 \%$ (fourteen percent) of the category quite understand; and 7\% (seven percent) understand categories. And 0\% (zero percent) category is very understanding. So the optimization program for rural tourism potential and the protracted and intensive role of BUMDesa needs to be carried out by the village government and BUMDesa.
\end{abstract}

Keywords: optimization, potential, village tourism, village government, BUM Desa.

\section{PENDAHULUAN}

Signifikannya peran sektor pariwisata sebagai salah satu andalan penghasil devisa negara dalam perekonomian Indonesia. Pemerintah Indonesia memberikan dorongan pengembangan potensi-potensi 
pariwisata sebagai destinasi wisata diwilayah pemerintah daerah kabupaten/kota. Pemerintah Daerah memiliki peran sangat strategis dalam penguatan usaha pariwisata, pengusaha pariwisata, dan industri pariwisata, sehingga tercipta kawasan strategis pariwisata. Penguatan dalam hal ini adalah mengintegrasikan BUMDesaBUMDesa sektor industri kreatif sebagai pendukung pariwisata, misalnya BUMDesa pengelola wisata, transportasi, kerajinan, kuliner, dan produk unggulan daerah.

Program Pengembangan Desa Wisata di Indonesia telah disepakati oleh tiga kementerian (Humas Kemenkop dan UKM, 2017), yaitu:

1. Kementerian Pariwisata.

2. Kementerian Pemangunan daerah Tertinggal dan Transmigrasi.

3. Kementerian Koperasi dan UKM.

Selanjutnya, menurut pemahaman peneliti maka berkaitan dengan pola strategi ketiga kementerian berkaitan Program Pembangunan Desa Wisata di Indonesia, dapat dijelaskan dengan tabel 1, berikut ini:

Tabel 1.

Pola Strategis Program Pembangunan Desa Wisata di Indonesia

\begin{tabular}{|c|l|l|}
\hline No & \multicolumn{1}{|c|}{ Kementerian } & \multicolumn{1}{c|}{ Keterangan } \\
\hline 1. & Kementerian Pariwisata & destinasi wisata desa dan penduduk desa sadar wisata. \\
\hline 2. & $\begin{array}{l}\text { Kementerian Pemangunan daerah } \\
\text { Tertinggal dan Transmigrasi }\end{array}$ & $\begin{array}{l}\text { prioritas dana desa untuk pembangunan infrastruktur dan } \\
\text { mengembangkan perekonomian pedesaan (salah satunya untuk } \\
\text { pengembangan desa wisata). }\end{array}$ \\
\hline 3. & Kementerian Koperasi dan UKM & $\begin{array}{l}\text { pelaku UKM di kawasan daerah desa wisata untuk membentuk } \\
\text { koperasi wisata. }\end{array}$ \\
\hline
\end{tabular}

Berkaitan dengan program pembangunan desa wisata di Indonesia, maka Desa Sugihwaras merupakan salah satu desa dalam wilayah Kabupaten Kediri yang merupakan desa yang terletak paling Timur wilayah Kecamatan Ngancar dan terletak didataran tinggi dengan ketinggian 500 - 600 M dari atas permukaan laut. Lokasi desa Sugihwaras Kecamatan Ngancar Kabupaten Kediri merupakan desa yang berada dikawasan wisata "Gunung Kelud" untuk itu keberadaan Desa Sugihwaras memiliki peran penting dalam optimalisasi pariwisata.

Selanjutnya, penelitian ini bertujuan untuk :

1. Mengetahui dan menganalisis potensi Desa Wisata Sugihwaras.

2. Mengetahui pemahaman pemerintah desa dan BPD Desa Wisata Sugihwaras terkait BUMDesa.

\section{TINJAUAN PUSTAKA}

Desa

Desa adalah Desa dan Desa adat atau yang disebut dengan nama lain, selanjutnya disebut Desa, adalah kesatuan masyarakat hukum yang memiliki batas wilayah yang berwenang untuk mengatur dan mengurus urusan pemerintahan, kepentingan masyarakat setempat berdasarkan prakarsa masyarakat, hak asal usul, dan/atau hak tradisional yang diakui dan dihormati dalam sistem pemerintahan Negara Kesatuan Republik Indonesia. (Permendesa No: 19 Tahun 2017 Bab 1 Pasal 1 ayat 1).

\section{Kepariwisataan}

Berdasarkan Undang-Undang Republik Indonesia Nomor 20 Tahun 2009 tentang Kepariwisataan BAB I pasal 1 ayat 3 (merupakan hasil penyesuaian dari Undang-Undang Nomor 9 Tahun 1990 tentang Kepariwisataan). Pariwisata adalah berbagai macam kegiatan wisata dan didukung berbagai fasilitas serta layanan yang disediakan oleh masyarakat, pengusaha, pemerintah, dan pemerintah daerah.

Undang-Undang Republik Indonesia Nomor 20 Tahun 2009 tentang Kepariwisataan BAB I pasal 1 ayat

5 Daya Tarik Wisata adalah segala sesuatu yang memiliki keunikan, keindahan, dan nilai yang berupa 
keanekaragaman kekayaan alam, budaya, dan hasil buatan manusia yang menjadi sasaran atau tujuan kunjungan wisatawan.

Undang-Undang Republik Indonesia Nomor 20 Tahun 2009 tentang Kepariwisataan BAB I pasal 1 ayat 6 Daerah tujuan pariwisata yang selanjutnya disebut Destinasi Pariwisata adalah kawasan geografis yang berada dalam satu atau lebih wilayah administratif yang di dalamnya terdapat daya tarik wisata, fasilitas umum, fasilitas pariwisata, aksesibilitas, serta masyarakat yang saling terkait dan melengkapi terwujudnya kepariwisataan.

Undang-Undang Republik Indonesia Nomor 20 Tahun 2009 tentang Kepariwisataan BAB I pasal 1 ayat 7 Usaha Pariwisata adalah usaha yang menyediakan barang dan/atau jasa bagi pemenuhan kebutuhan wisatawan dan penyelenggaraan pariwisata.

Undang-Undang Republik Indonesia Nomor 20 Tahun 2009 tentang Kepariwisataan BAB I pasal 1 ayat 8 Pengusaha Pariwisata adalah orang atau sekelompok orang yang melakukan kegiatan usaha pariwisata.

Undang-Undang Republik Indonesia Nomor 20 Tahun 2009 tentang Kepariwisataan BAB I pasal 1 ayat 9 Industri Pariwisata adalah kumpulan usaha pariwisata yang saling terkait dalam rangka menghasilkan barang dan/atau jasa bagi pemenuhan kebutuhan wisatawan dalam penyelenggaraan pariwisata.

Undang-Undang Republik Indonesia Nomor 20 Tahun 2009 tentang Kepariwisataan BAB I pasal 1 ayat 10 Kawasan Strategis Pariwisata adalah kawasan yang memiliki fungsi utama pariwisata atau memiliki potensi untuk pengembangan pariwisata yang mempunyai pengaruh penting dalam satu atau lebih aspek, seperti pertumbuhan ekonomi, sosial dan budaya, pemberdayaan sumber daya alam, daya dukung lingkungan hidup, serta pertahanan dan keamanan.

\section{Konsep BUM Desa}

Undang-Undang Nomor: 6 Tahun 2014 tentang Desa BAB I Ayat 1 Pasal 6 Badan Usaha Milik Desa, yang selanjutnya disebut BUM Desa, adalah badan usaha yang seluruh atau sebagian besar modalnya dimiliki oleh Desa melalui penyertaan secara langsung yang berasal dari kekayaan Desa yang dipisahkan guna mengelola aset, jasa pelayanan, dan usaha lainnya untuk sebesar- besarnya kesejahteraan masyarakat Desa.

BUMdes Perspektif Perundang-undangan:

1. Undang-Undang Nomor: 6 Tahun 2014 menuliskan, bumdes milik pemerintah desa karena didirikan melalui peraturan desa dan dimodali dari APB Desa. Undang-undang mewajibkan bumdes menyerahkan keuntungan sebagai PAD ke dalam APB Desa. Dengan begitu, pemerintah desa dapat menggunakan profit badan usaha bagi pembangunan, pemberdayaan masyarakat, hingga bantuan sosial golongan miskin.

2. Peraturan Pemerintah Nomor 43 Tahun 2014 juga menempatkan kepala desa sebagai pembina bumdes, sementara pengelolanya wajib berada di luar pemerintahan agar terhindar dari kolusi otokratif.

3. Undang-undang menegaskan bumdes sebagai urusan eksekutif desa sehingga wewenang penataan selayaknya pada Kemendagri. Namun, PP No 47/2015 memilah urusan bumdes kepada Kementerian Desa PDTT lantaran mengiranya sebagai wadah pemberdayaan warga.

4. Permendesa no. 19 Tahun 2017 berisi tentang ketentuan prioritas penggunaan Dana Desa untuk tahun 2018. Prioritas Penggunaan Dana Desa 2018 diutamakan untuk 4 Program Unggulan Kemendesa, yaitu kegiatan produk unggulan Desa atau kawasan perdesaan (PRUKADES), BUM Desa atau BUM Desa Bersama, embung, dan Sarana Olahraga Desa.

\section{METODE PENELITIAN}

Populasi

Populasi terdiri 14 orang yang diambil tanpa membedakan jenis kelamin, pendidikan, dan pengalaman kerja. Selanjutnya sampel diambil dari keseluruhan populasi. 
Jurnal Manajemen dan Bisnis MEDIA EKONOMI, Vol . XIX No 2 Juli 2019

\section{Metode pengumpulan data}

Sumber data primer diperoleh dari kuesioner tertutup berjumlah 10 item soal pertanyaan dengan skor penilaian jawaban 1 = benar dan $0=$ salah, kepada pemerintah desa (kades dan perangkat desa) dan Badan Permusyawaratan Desa (BPD) dengan pertanyaan pilihan ganda memilih yang tepat kemudian dijelaskan dengan statistik deskriptif (prosentase). Selain itu, data primer juga didapat dari hasil observasi dan wawancara. Sedangkan data sekunder yang diperoleh dari dokumen yang berkaitan dengan dokumen data potensi desa.

\section{HASIL DAN PEMBAHASAN}

\section{Potensi Desa Wisata Sugihwaras}

\section{Demografi}

Demografi adalah studi ilmiah tentang penduduk, terutama tentang jumlah, sturuktur dan perkembangannya. Berdasarkan data profil desa, jumlah penduduk Desa Sugihwaras adalah 3.363 jiwa dengan komposisi tersaji dalam tabel berikut :

a. Jumlah penduduk di masing - masing dusun.

Tabel 2.

Jumlah penduduk di masing - masing dusun

\begin{tabular}{|l|l|l|l|l|l|l|}
\hline No & \multicolumn{1}{|c|}{ DUSUN } & \multicolumn{1}{|c|}{ RUMAH } & \multicolumn{1}{|c|}{ KK } & \multicolumn{1}{|c|}{ Lk } & \multicolumn{1}{|c|}{ Pr } & \multicolumn{1}{|c|}{ JUMLAH } \\
\hline 1 & REJOMULYO & 363 & 458 & 565 & 612 & 1.177 \\
\hline 2 & SUGIHWARAS & 277 & 363 & 502 & 521 & 1.023 \\
\hline 3 & MULYOREJO & 295 & 402 & 582 & 581 & 1.163 \\
\hline \multicolumn{2}{|l|}{ JUMLAH TOTAL } & 935 & 1.223 & 1.649 & 1.714 & 3.363 \\
\hline
\end{tabular}

b. Jumlah Penduduk menurut umur

Tabel 3.

Jumlah Penduduk menurut umur

\begin{tabular}{|l|l|l|l|l|}
\hline \multicolumn{1}{|c|}{ No } & \multicolumn{1}{|c|}{ Kel. Umur } & \multicolumn{1}{c|}{ Laki-laki } & Perempuan & Jumlah \\
\hline 1 & $0-6$ & 122 & 98 & 220 \\
\hline 2 & $7-12$ & 122 & 134 & 256 \\
\hline 3 & $13-14$ & 85 & 77 & 162 \\
\hline 4 & $15-18$ & 98 & 126 & 224 \\
\hline 5 & $19-25$ & 197 & 231 & 428 \\
\hline 6 & $26-35$ & 327 & 346 & 673 \\
\hline 7 & $36-45$ & 267 & 307 & 574 \\
\hline 8 & $46-50$ & 159 & 170 & 329 \\
\hline 9 & $51-60$ & 102 & 113 & 215 \\
\hline 10 & $61-75$ & 203 & 214 & 417 \\
\hline 11 & $>75$ & 72 & 70 & 142 \\
\hline & JUMLAH & 1.649 & 1.714 & 3.363 \\
\hline
\end{tabular}


Jurnal Manajemen dan Bisnis MEDIA EKONOMI, Vol . XIX No 2 Juli 2019

c. Kondisi Jalan

- Jalan tanah

- Jalan makadam

$=\quad 4.000 \mathrm{~m}$

- Jalan beton

$=\quad 1.600 \mathrm{~m}$

- Jalan aspal

$=\quad--\quad \mathrm{m}$

$=6.000 \mathrm{~m}$

d. Sarana dan prasarana desa :

Tabel 4.

Sarana dan prasarana desa

\begin{tabular}{|l|l|l|l|l|l|l|}
\hline Balai Desa & TK & SD & PUSTU & Masjid & Mushola & Gereja \\
\hline 1 unit & 3 unit & 2 unit & 1 unit & 5 Buah & 7 Buah & Buah \\
\hline
\end{tabular}

\section{Keadaan Sosial}

Kondisi sosial masyarakat Desa Sugihwaras dapat dilihat dari keadaan sebagai berikut :

\section{a. Tingkat Pendidikan}

Tabel 5.

Tingkat Pendidikan

\begin{tabular}{|l|l|r|r|r|}
\hline No & \multicolumn{1}{|c|}{ Pendidikan } & \multicolumn{1}{|c|}{ Laki - laki } & Perempuan & \multicolumn{1}{c|}{ Jumlah } \\
\hline 1 & SD / MI & 134 & 155 & 289 \\
\hline 2 & SMP / MTs & 70 & 75 & 145 \\
\hline 3 & SMA / SMK / MA & 30 & 35 & 75 \\
\hline 4 & PT / Perguruan Tinggi & 10 & 15 & 25 \\
\hline
\end{tabular}

\section{b. Agama}

Tabel 6.

Agama

\begin{tabular}{|l|l|r|l|l|}
\hline No & Agama & Laki - laki & Perempuan & Jumlah \\
\hline 1 & Islam & 1.550 & 1.612 & 3.162 \\
\hline 2 & Kristen & 99 & 102 & 201 \\
\hline 3 & Katolik & & & \\
\hline 4 & Hindu & - & - & - \\
\hline 5 & Budha & - & - & - \\
\hline 6 & Konghucu & - & - & - \\
\hline
\end{tabular}




\section{c. Fasilitas Sosial}

Tabel 7.

Fasilitas Sosial

\begin{tabular}{|c|c|c|}
\hline No & Fasilitas & Jumlah \\
\hline 1 & $\begin{array}{l}\text { Tempat Ibadah } \\
\text { Masjid } \\
\text { Mushola } \\
\text { Gereja } \\
\text { Pura } \\
\text { Wihara } \\
\text { Klenteng }\end{array}$ & $\begin{array}{l}5 \\
7 \\
1 \\
- \\
-\end{array}$ \\
\hline 2 & $\begin{array}{l}\text { Sekolah } \\
\text { TK } \\
\text { Sekolah Dasar } \\
\text { Sekolah Menegah Pertama } \\
\text { Sekolah Menengah Atas } \\
\end{array}$ & $\begin{array}{l}3 \\
2 \\
- \\
-\end{array}$ \\
\hline 3 & $\begin{array}{l}\text { Kesehatan } \\
\text { Puskesmas } \\
\text { Puskesmas Pembantu } \\
\text { Posyandu }\end{array}$ & $\begin{array}{l}- \\
1 \\
3\end{array}$ \\
\hline 4 & $\begin{array}{l}\text { Keamanan } \\
\text { Poskamling }\end{array}$ & 31 \\
\hline
\end{tabular}

Berdasarkan hasil wawancara, 06 Maret 2019 dengan kepala desa dan sekdes Desa Sugihwaras Kecamatan Ngancar sebagai berikut:

1. BUMDesa sudah memiliki nama yaitu "Kelud Mandiri" tetapi belum terdapat manajemen pengelolaan (baru sebatas nama saja).

2. Terdapat pengelola Desa Wisata tetapi tidak aktif, hanya kondisional saja, dengan programnya pengelolaan "home stay" yang dimiliki warga.

3. Potensi usaha yang dijalankan warga Desa Sugihwaras kebun nanas yang luas dan lahan perkebunan yang luas, sehingga rumput untuk ternak melimpah.

\section{Pemahaman Pemerintah Desa dan BPD Desa Wisata Sugihwaras terkait BUMDesa}

Item Pertanyaan Pemahaman Berkaitan BUMDesa

1. BUMDesa singkatan dari:

2. Undang-Undang tentang BUMDesa adalah

3. Bidang usaha BUMDesa yang dijalankan didasarkan pada;

4. Legalitas BUMDesa, disahkan melalui:

5. AD/ART disahkan, melalui:

6. Penyertaan Modal di BUMDesa, disahkan melalui:

7. Organisasi Pengelola BUMDesa, terdiri kecuali:

8. Modal BUMDesa, berasal dari:

9. Pengurus BUMDesa, disahkan melalui:

10. Penyertaan awal modal BUMDesa, disyaratkan adanya: 
Jurnal Manajemen dan Bisnis MEDIA EKONOMI, Vol . XIX No 2 Juli 2019

Hasil pengukuran berbasis item pertanyaan kuesioner:

Tabel 8.

Hasil pengukuran berbasis item pertanyaan kuesioner

\begin{tabular}{|c|l|c|c|}
\hline No & \multicolumn{1}{|c|}{ Jenis Pertanyaan } & $\begin{array}{c}\text { Jawaban } \\
\text { benar }\end{array}$ & Mayoritas responden \\
\hline 1. & BUMDesa singkatan & $85 \%$ & Paham \\
\hline 2. & Undang-Undang tentang BUMDesa adalah & $42 \%$ & kurang paham \\
\hline 3. & Bidang usaha BUMDesa yang dijalankan didasarkan pada & $71 \%$ & cukup paham \\
\hline 4. & Legalitas BUMDesa, disahkan melalui & $28,5 \%$ & kurang paham \\
\hline 5. & AD/ART disahkan, melalui & $42 \%$ & kurang paham \\
\hline 6. & Penyertaan Modal di BUMDesa, disahkan melalui & $28,5 \%$ & kurang paham \\
\hline 7. & Organisasi Pengelola BUMDesa, terdiri kecuali & $71 \%$ & cukup paham \\
\hline 8. & Modal BUMDesa, berasal dari & $92 \%$ & sangat paham \\
\hline 9. & Pengurus BUMDesa, disahkan melalui & $28,5 \%$ & kurang paham \\
\hline 10. & Penyertaan awal modal BUMDesa, disyaratkan adanya & $100 \%$ & sangat paham \\
\hline
\end{tabular}

Keterangan skor pada tabel 8 sebagai berikut :

\begin{tabular}{|c|c|}
\hline $0-60$ & sangat kurang paham \\
\hline $61-70$ & kurang paham \\
\hline $71-80$ & cukup paham \\
\hline $81-90$ & Paham \\
\hline $91-100$ & sangat paham \\
\hline
\end{tabular}

Hasil pengukuran berdasarkan keseluruhan responden

Tabel 9

Hasil pengukuran berdasarkan keseluruhan responden

\begin{tabular}{|c|r|r|r|}
\hline Skor Benar dari Keseluruhan Soal & Jumlah Responden & Keterangan & $\begin{array}{c}\text { Prosentase } \\
\text { Pemahaman } \\
\text { BUMDesa }\end{array}$ \\
\hline $40 \%$ & 1 orang & sangat kurang paham & \multirow{2}{*}{$78,57 \%$} \\
\hline $50 \%$ & 5 orang & sangat kurang paham & $7,14 \%$ \\
\hline $60 \%$ & 5 orang & sangat kurang paham & $7,14 \%$ \\
\hline $70 \%$ & 1 orang & kurang paham & $100 \%$ \\
\hline $100 \%$ & 1 orang & sangat paham & Jumlah \\
\hline Jumlah & 14 orang & \multicolumn{2}{|r|}{}
\end{tabular}

\section{PENUTUP}

Hasil penelitian yang terkait dengan Optimalisasi Desa Wisata Sugihwaras Kecamatan Ngancar dalam perspektif BUMDesa oleh pemerintah desa dan BPD selaku pembuatan kebijakan.

1. Potensi Desa Wisata Sugihwaras belum terkelola dengan standar padahal memiliki potensi. BUMDesa sudah memiliki nama yaitu "Kelud Mandiri" tetapi belum terdapat manajemen pengelolaan (baru sebatas nama saja). Terdapat pengelola Desa Wisata tetapi tidak aktif, hanya kondisional saja, dengan programnya pengelolaan 
Jurnal Manajemen dan Bisnis MEDIA EKONOMI, Vol . XIX No 2 Juli 2019

"home stay" yang dimiliki warga. Potensi usaha yang dijalankan warga Desa Sugihwaras kebun nanas yang luas dan lahan perkebunan yang luas, sehingga rumput untuk ternak melimpah.

2. Terdapat pemahaman terkait BUMDesa dengan hasil sebagai berikut: $78,57 \%$ (tujuh puluh delapan koma lima puluh tujuhpersen) kategori sangat kurang paham; 7,14\% (tujuh koma empat belas persen) kategori kurang paham; 7,14 \% (tujuh koma empat belas persen)kategori sangat paham. Jadi program optimalisasi potensi desa wisata dan peran BUMDesa secara berlanjutan dan intensif perlu dilakukan oleh pihak pemerintah desa dan BUMDesa.

Untuk selanjutnya disarankan agar melakukan penelitian pengalian potensi secara detail dan diteruskan dengan tindak lanjut program optimalisasi desa wisata dan peran BUMDesa secara terstruktur dan berkesinambungan oleh stakeholder dan shareholder terkait.

\section{DAFTAR PUSTAKA}

Humas Kementerian Koperasi dan UKM. Denpasar, 21 Mei 2017 http://www.depkop.go.id/content/read/tigakementerian-dukung-pengembangan-desa-wisata/

Peraturan Menteri Desa, Pembangunan Daerah Tertinggal, dan Transmigrasi Republik Indonesia Nomor 19 Tahun 2017 tentang Penetapan Prioritas Penggunaan Dana Desa Tahun 2018.

Peraturan Pemerintah Nomor 43 Tahun 2014 tentang BUMDesa.

Undang-Undang Republik Indonesia Nomor 20 Tahun 2009 tentang Kepariwisataan.

Undang-Undang Nomor: 6 Tahun 2014 tentang Desa. 